\title{
HUBUNGAN ANTARA PENGETAHUAN ORANG TUA TENTANG PHBS DENGAN PERILAKU PENCEGAHAN ISPA
}

\author{
Ratih Dwilestari Puji utami $^{1}$, Nur Rahmawati ${ }^{2}$, Martina Eka Cahyaningtyas ${ }^{3}$ \\ 1,2,3 Program Studi Sarjana keperawatan dan Profesi Ners, Universitas Kusuma Husada \\ Surakarta \\ ratihaccey@gmail.com
}

\begin{abstract}
Abstrak
Pendahuluan: Infeksi Saluran Pernafasan Akut merupakan salah satu penyebab utama kunjungan pasien di Puskesmas (40\%-60\%) dan rumah sakit (15\%-30\%), selain itu ISPA juga menjadi urutan pertama penyebab kematian pada kelompok bayi dan balita. ISPA merupakan penyebab kematian bayi terbesar di Indonesia dengan persentase 32,10\% dari seluruh kematian balita. Orang tua yang memiliki tingkat pengetahuan yang tinggi, memiliki kecenderungan berperilaku hidup bersih dan sehat, tidak dilakukannya Perilaku Hidup Bersih dan Sehat (PHBS) meningkatkan resiko sebesar 5 kali lipat terjadinya ISPA berulang pada balita. Orang tua berperan dalam upaya pencegahan ISPA, antara lain pencegahan tertularnya penyakit dan perbaikan perilaku kesehatan seperti kebersihan perorangan, pemilihan makanan, sanitasi, pencahayanan, pengadaan udara yang bersih dan beberapa upaya lainnya.

Tujuan: penelitian ini bertujuan untuk menganalisis hubungan antara tingkat pengetahuan orang tua tentang Perilaku Hidup Bersih dan Sehat dengan perilaku pencegahan ISPA di wilayah Posyandu Kalingga Banyuanyar Surakarta.

Metode: Desain penelitian ini menggunakan pendekatan cross sectional, yang bertujuan untuk mengetahui hubungan antar variabel, dengan variabel independen yaitu pengetahuan orang tua tentang PHBS dan variabel dependen yaitu perilaku pencegahan ISPA diidentifikasi dalam satu waktu melalui purposive sampling dengan jumlah sampel sebanyak 39 responden.

Hasil: Dari penelitian didapatkan $p$ value 0,023 dengan nilai $\mathrm{p}<0,05$. Sebanyak 59\% responden memiliki pengetahuan sedang tentang PHBS pada tingkat sedang dan $84,6 \%$ responden memiliki perilaku pencegahan ISPA pada tingkat sedang.

Kesimpulan: Ada hubungan bermakna antara antara pengetahuan orang tua tentang Perilaku Hidup Bersih dan Sehat dengan perilaku pencegahan ISPA di Posyandu Balita Kalingga Kelurahan Banyuanyar Surakarta.
\end{abstract}

Kata kunci: Pengetahuan, PHBS, Perilaku Pencegahan ISPA.

\begin{abstract}
Background: Accute Respiratory Tract Infection(ARI) is one of the main causes of patient visits in health centers $(40 \%-60 \%)$, also first cause of death in infants and toddlers. $32.10 \%$ death of children under five years in Indonesia is caused by ARI. Parents who have a high level of knowledge, have a tendency to behave clean and healthy, unclean and unhealthy life behaviors 5-fold increase the risk of recurring ARI in children under five years. Families play a role in efforts to prevent ARI, including prevention of disease transmission and improvement of health behaviors such as personal hygiene, food selection, sanitation, lighting, clean air supply and several other efforts.

Purpose: This study aims to analyze the relationship between the level of maternal knowledge about Clean and Healthy Behavior with ARI prevention behavior.

Methods: The design of this study uses cross sectional, this design is to determine the relationship between variables. Independent variable of this research is the parent's knowledge about clean and healthy life behavior (PHBS) and the dependent variable is ARI's prevention behavior. This variables was identified at one time through purposive sampling.
\end{abstract}


Result: $\mathrm{p}$ value of this research is 0,023 . 59\% of respondents have a moderate level of knowledge about clean and healthy life behavior (PHBS) and $84.6 \%$ of respondents have moderate level of ARI prevention behavior.

Conclusion: There is a significant correlation between parents' knowledge about Clean and Healthy Life Behavior (PHBS) with ARI prevention behavior.

Key words: Knowledge, Clean and Healthy Life Behavior (PHBS), ARI prevention behavior

\section{Pendahuluan}

ISPA merupakan infeksi akut yang menyerang salah satu bagian/lebih dari saluran napas mulai hidung sampai alveoli termasuk adneksanya (sinus, rongga telinga tengah, pleura). Terdapat 156 juta episode baru ISPA di dunia per tahun dimana 151 juta episode $(96,7 \%)$ terjadi di negara berkembang. Kasus ISPA terbanyak terjadi di India (43 juta), China (21 juta) dan Pakistan (10juta) dan Bangladesh, Indonesia, Nigeria masing-masing 6 juta episode (Kementrian Kesehatan RI, 2011). Di Indonesia, kejadian ISPA hampir terjadi tiap bulannya (Maharani, Yani, dan Lestari, 2013). ISPA merupakan salah satu penyebab utama kunjungan pasien di Puskesmas (40\%-60\%) dan rumah sakit (15\%-30\%) dan menjadi urutan pertama penyebab kematian pada kelompok bayi dan balita. Survei mortalitas yang dilakukan oleh Subdit ISPA tahun 2016 menempatkan ISPA/ISPA sebagai penyebab kematian bayi terbesar di Indonesia sebesar $32,10 \%$ dari seluruh kematian balita (Susanti, 2017).

Hadisaputra, Suparta, dan Ananda (2015), ada beberapa faktor yang mempengaruhi angka kejadian ISPA pada balita, antara lain: perilaku hidup bersih dan sehat dan status gizi balita. Perilaku hidup bersih dan sehat yang tidak baik sapat meningkatkan kejadian ISPA 2 sampai 12 kali lebih banyak pada balita. Tiga tahapan pencegahan ISPA menurut Fithria (2018), yaitu pencegahan tingkat pertama meliputi imunisasi, pemberian makanan yang bergizi, membuang sampah pada tempatnya, dan ventilasi udara segar setiap pagi; sedangkan pencegahan tingkat kedua meliputi: perawatan anak demam, pemeriksaan kepelayanan kesehatan saat anak memiliki tanda-tanda ISPA yaitu batuk, pilek dan demam; pencegahan tingkat ketiga meliputi: membawa balita ke pelayanan kesehatan saat balita sakit.

Elvandari, Briawan, Tanziha tahun 2018 menambahkan bahwa PHBS merupakan modal utama dalam pencegahan ISPA. Data Kementrian Kesehatan tahun 2013 menunjukkan bahwa PHBS rumah tangga di Indonesia baru mencapai 55,6\%, 
sedangkan di Jawa Tengah sebesar 75,1\%, di Surakarta sendiri pada tahun 2016 target PHBS sebesar 55\% dan terealisasi sebesar 56,5\% dengan capaian 102,7\%, dan tahun 2021 ditargetkan capaian PHBS sebesar 80\% sehingga masih tersisa 23,5\% target yang belum tercapai (Pemkot Surakarta, 2017).

Orang tua yang memiliki tingkat pengetahuan yang tinggi juga memiliki perilaku hidup bersih dan sehat yang tinggi pula, hal ini ditunjukkan dengan adanya hubungan yang signifikan antara tingkat pengetahuan orang tua dengan perilaku hidup bersih dan sehat. Orang tua yang memiliki tingkat pengetahuan yang tinggi mengenai PHBS memiliki kecenderungan untuk menerapkan ilmu yang dimiliki dalam tatanan kehidupan sehari-hari dalam rumah tangga seperti pengunaan air bersih, sanitasi dan lain sebagainya (Siswani dan Rizky, 2017). Keluarga memiliki peran yang sangat penting dalam PHBS (Rompas, Ismanto dan Oroh , 2018), peran orang tua yaitu membimbing, mengajarkan, memberikan pengertian, mengingatkan dan menyediakan fasilitas kepada anak agar anak dapat membiasakan dalam menjaga kebersihan dan kesehatan, selain itu orang tua juga berperan dalam pengawasan anak dalam perilaku hidup bersih dan sehat. PHBS yang tidak diterapkan dalam keluarga, akan cenderung memiliki anak dengan kesehatan yang tidak baik, seperti kebiasaan mencuci tangan sebelum makan dapat mengurangi morbiditas sebesar 2-3 kali lipat (Elvandari, Briawan, Tanziha, 2018).

\section{Tujuan}

Menganalisis hubungan antara tingkat pengetahuan orang tua tentang PHBS dengan perilaku pencegahan ISPA di Posyandu Kalingga Banyuanyar Surakarta.

\section{Metode}

Penelitian ini menggunakan pendekatan cross sectional, desain cross sectional merupakan desain penelitian analitik yang bertujuan untuk mengetahui hubungan antar variabel, dimana variabel independen dan variabel dependen diidentifikasi dalam satu waktu (Dharma, 2013). Variabel independent dalam penelitian ini adalah Pengetahuan orang tua tentang PHBS dan Perilaku pencegahan ISPA yang keduanya memiliki skala data ordinal. Penelitian ini dilakukan di Posyandu Kalingga Banyuanyar pada bulan Maret 2019, dengan 
jumlah sampel sebanyak 39 responden berdasarkan rumus Slovin (Nursalam, 2013), yaitu orang tua atau ayah dari balita yang mengikuti program posyandu dengan pendekatan purposive sampling. Uji statistik yang digunakan dalam penelitian ini adalah uji Spearman Rank yaitu untuk menguji hubungan antara variabel independen dan variable dependen berskala ordinal (Dahlan, 2014).

\section{Hasil}

a. Pekerjaan Responden

Hasil kuesioner tentang pekerjaan responden dapat diperoleh hasil sebagai berikut:

Tabel 4.1 Deskripsi Variabel Pekerjaan Responden

\begin{tabular}{ccc}
\hline Pekerjaan & Jumlah & Persentase (\%) \\
\hline Bekerja & 19 & 48,7 \\
Tidak Bekerja & 20 & 51,3 \\
Jumlah & 39 & 100 \\
\hline
\end{tabular}

Sumber : data primer diolah, 2018

Hasil penelitian menunjukkan bahwa mayoritas responden adalah tidak bekerja yaitu sebanyak 20 responden $(51,3 \%)$.

b. Pengetahuan tentang Perilaku Hidup Bersih dan Sehat

Hasil kuesioner tentang pengetahuan responden mengenai PHBS dapat diperoleh hasil sebagai berikut:

Tabel 4.2 Deskripsi Variabel Pengetahuan orang tua tentang PHBS

\begin{tabular}{ccc}
\hline Pengetahuan & Jumlah & Persentase (\%) \\
\hline Rendah & 3 & 7,7 \\
Sedang & 23 & 59,0 \\
Tinggi & 13 & 33,3 \\
Jumlah & 39 & 100 \\
\hline
\end{tabular}

Sumber : data primer diolah, 2018

Hasil penelitian menunjukkan bahwa mayoritas responden memiliki pengetahuan tentang PHBS pada tingkat sedang sebanyak 23 responden (59\%). 
c. Perilaku Pencegahan ISPA

Hasil kuesioner tentang perilaku pencegahan ISPA dapat diperoleh hasil sebagai berikut:

Tabel 4.3 Deskripsi Variabel Perilaku Pencegahan ISPA

\begin{tabular}{ccc}
\hline Perilaku & Jumlah & Persentase (\%) \\
\hline Rendah & 1 & 2,6 \\
Sedang & 33 & 84,6 \\
Tinggi & 5 & 12,8 \\
Jumlah & 39 & 100 \\
\hline
\end{tabular}

Sumber : data primer diolah, 2018

Hasil penelitian menunjukkan bahwa mayoritas responden memiliki perilaku pencegahan ISPA pada tingkat sedang sebanyak 33 responden $(84,6 \%)$.

d. Analisis Bivariat Hubungan Pengetahuan Orang Tua tentang PHBS dengan Perilaku Pencegahan ISPA

Hasil perhitungan spearman rank hubungan Pengetahuan Orang Tua tentang PHBS dengan Perilaku Pencegahan ISPA dilihat pada tabel sebagai berikut:

Tabel 4.4 Hubungan Pengetahuan Orang Tua tentang PHBS dengan Perilaku Pencegahan ISPA

\begin{tabular}{ccc}
\hline r hitung & p-value $(\%)$ & Keputusan \\
\hline 0,363 & 0,023 & H0 ditolak
\end{tabular}

Sumber : data primer diolah, 2018

Hasil uji spearman rank diperoleh nilai $\mathrm{r}$ hitung 0,363 dengan $p$ value $(0,023<$ 0,05), berarti ada hubungan pengetahuan orang tua tentang PHBS dengan perilaku pencegahan ISPA di Posyandu Balita Kalingga Kelurahan Banyuanyar Surakarta.

\section{Pembahasan}

Hasil penelitian menunjukkan bahwa mayoritas responden adalah tidak bekerja yaitu sebanyak 20 responden $(51,3 \%)$, sedangkan responden yang bekerja sebanyak 19 responden atau 48,7\%. Status pekerjaan yang paling banyak adalah wirausaha sehingga orang tua memiliki banyak waktu untuk mengantarkan balita untuk berkunjung ke posyandu. Menurut Firdausia (2013), ada hubungan antara pekerjaan dengan perilaku pencegahan ISPA, orang tua yang tidak bekerja memiliki waktu hampir 24 jam dengan anak dan merawat anak. Ibu yang bekerja 
memiliki tantangan yang lebih banyak karena memiliki konflik peran, ibu yang bekerja harus dapat membagi peran dan waktunya antara bekerja dan merawat anak, selain itu ibu yang tidak bekerja dapat memberikan nutrisi yang lebih baik jika dibandingkan dengan ibu yang bekerja. Hal ini berbeda dengan pendapat Syahidi, Gayatri dan Bantas (2013), yang menambahkan bahwa pekerjaan responden tidak memiliki pengaruh terhadap kejadian ISPA pada balita. ISPA lebih banyak terjadi pada kelas sosial rendah dibandingkan dengan kelas sosial tinggi. Jika dibandingkan dengan status pekerjaan, kepadatan penduduk, status nutrisi anak, dan asap rokok lebih berpengaruh terhadap kejadian ISPA.

Berdasarkan data dilapangan, kebanyakan ibu yang tidak bekerja memiki status sosial yang rendah, penghasilan yang rendah, kepadatan hunian yang tinggi, serta tingkat pengetahuan dan pendidikan yang rendah. Hal ini mempengaruhi pemenuhan kebutuhan nutrisi yang berpengaruh pada sistem imun anak; ketersediaan sarana dan prasarana untuk memenuhi pelayanan kesehatan anak; serta pengetahuan dan ketrampilan mencegah dan merawat anak dengan ISPA. Sedangkan ibu yang bekerja memilih untuk memperkerjakan pengasuh untuk memenuhi kebutuhan perawatan pada balita.

Syahidi, Gayatri dan Bantas (2013), menyatakan bahwa tingkat pengetahuan responden berpengaruh pada kejadian ISPA pada balita. Responden yang memiliki pengetahuan tetang PHBS yang baik menunjukkan upaya pencegahan, dan perawatan ISPA yang baik pula. Prihanti dkk, 2018 menambahkan bahwa pengetahuan membentuk keyakinan tertentu yang membuat seseorang berperilaku sesuai dengan keyakinan tersebut. Ibu yang mempunyai pengetahuan baik mengenai perilaku hidup bersih dan sehat, memiliki kecenderungan untuk berperilaku hidup bersih dan sehat yang baik pada tatanan rumah tangga. Pengetahuan mengenai PHBS dipengaruhi oleh beberapa faktor seperti tingkat pendidikan, kemudahan terhadap akses informasi, dan pengalaman pribadi. Fakta dilapangan didapatkan bahwa mayoritas responden memiliki pengetahuan tentang PHBS dalam tingkat sedang, dan hal ini berbanding lurus dengan perilaku pencegahan ISPA yang juga berada pada tingkat sedang, sehingga dapat disimpulkan bahwa ada kecenderungan pengetahuan mengenai PHBS berbanding lurus dengan perilaku pencegahan ISPA.

Husna, Kurniawati, dan Qur'aniati (2019), menyatakan bahwa perilaku 
responden mengenai pencegahan ISPA dipengaruhi oleh beberapa faktor seperti tingkat pendidikan responden, informasi, sarana dan prasarana. Perilaku pencegahan ISPA dimulai dari upaya untuk mencari informasi mengenai pencegahan penyakit ISPA, modifikasi lingkungan, pemenuhan nutrisi, sirkulasi udara dan ventilasi, serta pencegahan penularan ISPA. Perilaku pencegahan ISPA yang kurang dimiliki oleh orang tua adalah kurangnya pemenuhan kebutuhan cairan, pengaturan ventilasi serta pengaturan kamar balita, responden tidak mengetahui bahwa kurangnya ventilasi dapat menyebabkan ISPA. Pada penelitian ini, perilaku pencegahan ISPA yang kurang berada pada kurangnya minat orang tua dalam mengikuti penyuluhan tentang ISPA, penggunaan masker, pengunaan obat nyamuk bakar, melarang anak untuk bermain ditempat yang berdebu, dan menjauhkan anak dari asap rokok.

Hasil uji statistik rank spearman menunjukkan ada hubungan antara pengetahuan orang tua tentang PHBS dengan perilaku pencegahan ISPA. Hal ini sesuai dengan penelitian Silviana (2014), yang menunjukkan bahwa ada hubungan antara pengetahuan ibu tentang pencegahan ISPA dengan perilaku pencegahan ISPA dengan $p$ value 0,022 . Perilaku yang didasari oleh pengetahuan memiliki kecenderungan untuk bersifat langgeng. Perilaku yang sudah menjadi kebiasaan biasanya melalui beberapa proses seperti analisis dan evaluasi, pengetahuan yang didapatkan seseorang diaplikasikan dalam bentuk perilaku yang kemudian dianalisis dan dievaluasi untuk memberikan justifikasi dengan kriteria yang ada dan diputuskan apakah perilaku akan diadaptasi menjadi sebuah kebiasaan atau tidak. Fitriani, dan Andriyani (2015), beberapa faktor yang mempengaruhi pengetahuan yaitu tingkat pendidikan, informasi, sosial budaya dan ekonomi, lingkungan, pengalaman, dan usia. Responden pada penelitian ini mayoritas adalah ibu rumah tangga sebanyak 51,2\% dengan tingkat pendidikan dan sosial ekonomi menengah kebawah, sehingga memiliki keterbatasan dari segi pengetahuan, pendidikan, akses informasi, sarana dan prasarana.

Pada penelitian ini, pengetahuan mengenai PHBS berada pada angka sedang yaitu sebanyak 59\% (Sumber data primer diolah, 2018). Menurut Elvandari, Briawan, dan Tanziha (2018), PHBS merupakan perilaku pencegahan individu dalam tatanan rumah tangga dari berbagai penyakit. Perilaku pencegahan ISPA sebaiknya dilakukan oleh ibu dan anggota keluarga yang lainnya seperti; 
cuci tangan dengan sabun, pemberian ASI ekslusif untuk mencegah penyakit dan memberikan kekebalan pasif pada anak, penggunaan air bersih, konsumsi sayur dan buah, dan tidak merokok didalam rumah. PHBS merupakan modal untuk pencegahan penyakit ISPA.

Penelitian ini memiliki keterbatasan dari segi desain yang hanya melihat keterkaitan antara variabel pengetahuan tentang PHBS dengan perilaku pencegahan ISPA, akan lebih baik lagi jika penelitian ini dikembangkan dalam bentuk penelitian intervensi. Intervensi yang dilakukan adalah edukasi mengenai PHBS rumah tangga yang dikaitkan dengan angka kejadian ISPA pada anak.

\section{Kesimpulan}

Simpulan dari penelitian ini adalah mayoritas (59\%) responden memiliki pengetahuan tentang PHBS pada tingkat sedang, demikian juga dengan perilaku pencegahan ISPA juga memiliki tingkat sedang $(84,6 \%)$. Ada hubungan bermakna antara pengetahuan orang tua tentang PHBS dengan perilaku pencegahan ISPA di Posyandu Balita Kalingga Kelurahan Banyuanyar Surakarta p value $(0,023<$ 0,05). Saran bagi Pelayanan kesehatan untuk meningkatkan upaya promosi mengenai PHBS di masyarakat, agar tercipta lingkungan sehat dan terbebas dari penyakit. Selain itu bagi orang tua, hendaknya meningkatkan upaya dalam mencari informasi, melaksanakan upaya PHBS dalam tatanan rumah tangga sehingga terhindar dari penyakit.

\section{Daftar Pustaka}

Dahlan. M. S. 2014. Statistic untuk kedokteran dan kesehatan. Salemba Medika: Jakarta.

Dharma, Kelana. 2013. Metodologi Penelitian Keperawatan. CV Trans Info Media: Jakarta.

Elvandari, Milliyantri., Dodik Briawan, dan Ikeu Tanziha. 2018. Perilaku Hidup Bersih Dan Sehat (Phbs) Dengan Morbiditas Anak Usia 1-3 Tahun Di Jawa Tengah https://journal.unsika.ac.id/index.php/HSG/article/view/1509. (diakses tanggal 18 Desember 2018).

Firdausia, Annisa. 2013. 'Hubungan Pendidikan dan Pekerjaan Ibu dengan Perilaku Pencegahan ISPA pada Balita di Wilayah Kerja Puskesmas Gang Sehat Pontianak'. Naskah Publikasi. Prodi Pendidikan Dokter FK Universitas Tanjungpura: Pontianak. 
Fitriani, N.L. dan S. Andriyani. 2015. Hubungan Antara Pengetahuan dengan Sikap Anak Usia Sekolah Akhir (10-12 tahun)Tentang Makanan Jajanan di SD Negeri II Tagog Apu Padalarang Kabupaten Bndung Barat Tahun 2015. http.www//ejournal.upi.edu/index.php/JPKI/article/view/ 1184. (diakses tanggal 18 Desember 2018).

Hadisaputra, Sugeng., Luzi Supart., dan Ridho Ananda. 2015. Faktor-Faktor Yang Berhubungan Dengankejadian Ispa Berulang Pada Balita Usia 3659 Bulan Di Puskesmas Kecamatan Cipayung. Jurnal Bidang Ilmu Kesehatan Vol. 5, No. 1, Juni 2015. halaman 345-355.

Husna, Kurniawati, Qur'aniati. 2019. Konseling Meningkatkan Perilaku Ibu Dalam Pencegahan Dan Perawatan Balita Infeksi Saluran Pernafasan Akut Di Wilayah Kerja Puskesmas Bangkalan. https://ejournal.unair.ac.id/CMSNJ/article/view/12398. (diakses tanggal 7 Oktober 2019).

Kementerian Kesehatan Republik Indonesia. 2011. 10 Perilaku Hidup Bersih dan Sehat di Rumah Tangga. Jakarta: Kemenkes RI.

Maharani, Dita, Finny Fitry Yani, dan Yuniar Lestari. 2013. Profil Balita Penderita Infeksi Saluran Nafas Akut Atas diPoliklinik Anak RSUP DR. M. Djamil Padang Tahun 2012-2013. http://jurnal.fk.unand.ac.id. (diakses tanggal 12 Februari 2019).

Nursalam. 2013. Metodologi Penelitian Ilmu Keperawatan. Jakarta: Salemba Medika.

Pemerintah Kota Surakarta. 2017. LKjIP Kota Surakarta Tahun 2017. $h t t p: / / w w w . g o o g l e . c o m / u r l ? s a=t \& r c t=j \& q=\&$ esrc $=s \&$ source $=w e b \& c d=1$ $\& c a d=r j a \& u a c t=8 \& v e d=2 a h U K E w j w 5 M X F 4 c H f A h W L Q Y 8 K H X w Q A v U Q$ FjAAegQICRAC\&url=http\%3A\%2F\%2Fppid.surakarta.go.id\%2Fwpcontent\%2Fuploads\%2F2017\%2F09\%2FLKJIP-KOTA-SURAKARTATAHUN-2016.pdf\&usg=AOvVaw2rWwBW0s6Pm6lOxAOPwkLh. (diakses tanggal 18 Desember 2018).

Prihanti, Sekar., DA Lista, R Habibi, II Arsinta, SP Hanggara, RP Galih, F Sinta. 2018. Faktor-Faktor Yang Mempengaruhi Tingkat Perilaku Hidup Bersih Dan Sehat Pada Tatanan Rumah Tangga Di Wilayah Kerja Puskesmas Poned X. Saintika Medika: Jurnal Ilmu Kesehatan dan Kedokteran Keluarga volume 14, no. 1, halaman 7-14.

Rompas, Riani., Amatus Yudi Ismanto, dan Wenda Oroh. 2018. Hubungan Peran Orang Tua Dengan Perilaku Hidup Bersih Dan Sehat Anak Usia Sekolah Di Sd Inpres Talikuran Kecamatan Kawangkoan Utara. https://ejournal.unsrat.ac.id/index.php/ jkp/issue/view/1880. (diakses tanggal 12 februari 2019).

Siswani, Sri dan dan Anggita Cahyani Rizky. 2018. Hubungan Antara Pengetahuan Ibu Rumah Tangga Dengan Penerapan PHBS Di Wilayah RW 
07 Kelurahan Cijantung Kecamatan Pasar Rebo Jakarta Timur Tahun 2017. Jurnal Kesehatan Masyarakat Vol. 2 No. 1 April 201, halaman 16-31.

Susanti. 2017. 'Analisis Program Penanggulangan Ispa Pada Balita Di Puskesmas Sungai Lansek Tahun 2017'. Diploma Thesis, Universitas Andalas. Universitas Respati Indonesia: Jakarta Timur.

Syahidi, Muhammad Habibi., Dwi Gayatria., Krisnawati Bantas. 2016. Faktorfaktor yang Mempengaruhi Kejadian Infeksi Saluran Pernapasan Akut (ISPA) pada Anak Berumur 12-59 Bulan di Puskesmas Kelurahan Tebet Barat, Kecamatan Tebet, Jakarta Selatan, Tahun 2013. Jurnal Epidemiologi Kesehatan Indonesia Volume 1 November - 2016 No. 1, halaman 23-27. 